\title{
DIREITOS SOCIAIS E CONTROLE JURISDICIONAL DE POLÍTICAS PÚBLICAS: UMA ABORDAGEM A PARTIR DOS CONTORNOS DO ESTADO CONSTITUCIONAL DE DIREITO'
}

\author{
José Sérgio da Silva Cristóvam²
}

Resumo: A concretização dos direitos sociais, a partir do controle jurisdicional de políticas públicas, vem ganhando um relevo todo especial, a partir do estabelecimento de um modelo de Estado constitucional de direito, fundado na satisfação dos direitos fundamentais. Esse é o objeto central do presente estudo, além de apresentar os limites e possibilidades de um efetivo ativismo judicial, comprometido com a satisfação dos direitos sociais e legitimado pelo discurso constitucional contemporâneo. Afora os aspectos eminentemente teóricos, inclusive com a proposta de um conceito jurídico de "políticas públicas", segue a análise do entendimento dos tribunais sobre o

10 presente artigo, que representa o aprofundamento de análises já publicadas anteriormente pelo autor, foi apresentado originalmente como trabalho de conclusão da Disciplina de "Seminários de Garantismo Jurídico", oferecida pelo Prof. Dr. Sérgio Urquhart de Cademartori, para o Curso de Doutorado (trimestre 2010.2), do Programa de Pós-Graduação em Direito da UFSC (CPGD/UFSC).

2 Doutorando em Direito Administrativo pela UFSC. Mestre em Direito Constitucional pela UFSC. Especialista em Direito Administrativo pelo CESUSC. Professor de Direito Administrativo da Escola Superior da Magistratura do Estado de Santa Catarina (ESMESC). Professor de Direito Administrativo da Escola Nacional de Administração (ENA/Brasil), em convênio com a École Nationale d'Administration (l'ENA/França). Professor Titular de Ciência Política e Teoria Geral do Estado e Professor Substituto de Direito Administrativo no Curso de Graduação em Direito da UNIDAVI, bem como em Cursos de Pós-Graduação em Direito da UNIDAVI, CESUSC, UNISUL, UNOESC, UnC e diversas outras instituições. Professor em cursos preparatórios para Concursos Públicos e Exames de Ordem, nas disciplinas de Direito Constitucional e Direito Administrativo. Membro fundador do Instituto de Direito Administrativo de Santa Catarina (IDASC). Assessor Jurídico do Sindicato dos Trabalhadores na Rede Estadual de Ensino de Santa Catarina (SINTE/ $\mathrm{SC})$. Advogado militante na seara do Direito Público, Sócio do Escritório Cristóvam \& Palmeira Advogados Associados S/C. E-mail: jscristovam@gmail.com 
assunto, apresentando os parâmetros do controle jurisdicional de políticas públicas. Por fim, concluise defendendo a relevância da temática abordada, inclusive para a consolidação de uma cultura de defesa da Constituição.

Palavras-chave: Direitos sociais. Controle jurisdicional. Políticas públicas. Estado constitucional de direito.

\section{INTRODUÇÃO}

Passadas as primeiras duas décadas pós-Constituição de 1988 e atingida a "maioridade civil" da (ainda políticosocialmente infante) "abertura democrática" brasileira, um dos debates mais recorrentes na comunidade jurídica nacional refere-se à concretização dos direitos sociais constitucionalmente assegurados. A Constituição de 1988, multicolorida pela vivificadora e extensa aquarela de direitos sociais constitucionalizados, acaba dando sinais de fenecimento (ou, quem sabe, somente saturação!), ante a rarefeita concretização de várias das suas promessas emancipatórias, libertárias e de igualdade social.

Os (até certo ponto) interessantes argumentos relacionados ao custo (econômico) da concretização das promessas da "Constituição cidadã”, as limitações orçamentárias e a doutrina da reserva do possível ${ }^{3}$, aliados a uma visível falta de talento e capacidade do Poder Público em "bem gerenciar" o orçamento público (planejamento orçamentário), bem como inúmeros "ruídos e interferências ilegítimas" (corrupção, Administração patrimonialista e ineficientes sistemas de controle) na eleição das prioridades da ação estatal, acabam por entravar ainda mais

3 Para o estudo mais aprofundado acerca da reserva do possível, dos limites orçamentários e da concretização dos direitos fundamentais, pode-se consultar, dentre outros: SARLET, Ingo Wolfgang; TIMM, Luciano Benetti (Org.). Direitos fundamentais, orçamento e reserva do possível. 2. ed. Porto Alegre: Livraria do Advogado, 2010. 
a concretização daquelas promessas festejadas na já distante primavera de $1988^{4}$.

Nesse contexto, o presente ensaio pretende debater a problemática que gravita em torno da concretização dos direitos sociais e do controle jurisdicional de políticas públicas, a partir dos contornos do Estado constitucional de direito ${ }^{5}$, com a análise da jurisprudência ${ }^{6}$ que vem sendo construída na defesa dos direitos fundamentais ${ }^{7}$ positivos, seus limites e possibilidades.

4 O debate sumamente relevante entre direito e economia (law and economics), sobretudo no que toca à eficiência administrativa e a concretização dos direitos fundamentais, encontra uma qualificada abordagem no estudo de Júlio César MARCELLINO JÚNIOR, na seguinte obra: MARCELLINO JÚNIOR, Júlio César. Princípio constitucional da eficiência administrativa: (des) encontros entre economia e direito. Florianópolis: Habitus, 2009.

5 Analisando o fenômeno do Estado de direito a partir de uma perspectiva diacrônica, Sérgio CADEMARTORI divide a progressiva consolidação deste modelo de Estado em "governo per leges", "governo sub lege" e "Estado constitucional de direito". O aparato de dominação per leges constitui-se num poder que se expressa por meio de leis gerais e abstratas, decorrentes da vontade geral. Os atributos de generalidade e abstração da norma jurídica garantem a igualdade formal e afastam o arbítrio da ação governamental, vez que vinculam os poderes às formalidades e procedimentos dispostos em lei. No "governo sub lege" ocorre a vinculação e submissão dos poderes ao Direito, condicionando, além das formalidades e procedimentos da ação governamental, o conteúdo de tal ação, vinculando o governo a determinadas matérias. O Estado constitucional marca o caráter plenamente normativo e vinculante das Constituições, implicando na superação da redução positivista do Direito à lei e do jurídico ao legislativo. Deste modo, os direitos fundamentais passam a se constituir em matérias sobre as quais os poderes do Estado não podem dispor, uma vez que se constituem no fundamento de legitimidade do próprio Estado e expressão inarredável das democracias modernas. A garantia dos direitos fundamentais de liberdade e a concretização dos direitos fundamentais positivos é o dever primeiro do Estado, condição de legitimidade dos poderes constituídos. CADEMARTORI, Sérgio. Estado de direito e legitimidade: uma abordagem garantista. 2. ed. Campinas (SP): Millennium, 2007, p. 06-26.

6 Impende, desde já, estabelecer que o termo "jurisprudência" aqui empregado, e como, de resto, nas demais partes deste ensaio, refere-se ao conjunto de decisões dos tribunais (como normalmente ocorre na cultura jurídica brasileira), diversamente do seu sentido clássico europeu, enquanto estudo da "ciência do Direito" ou o que se pode entender por "teoria geral do Direito". Para o estudo da "jurisprudência" nesse último sentido, pode-se consultar, dentre inúmeros outros, a sempre lembrada "tópica e jurisprudência" de Theodor VIEHWEG. VIEHWEG, Theodor. Tópica y jurisprudencia. Traducción de Luis Díez-Picazo Ponce de Leon. Madrid: Taurus, 1964.

$7 \mathrm{O}$ aprofundamento do estudo sobre a teoria dos direitos fundamentais pode ser buscado a partir das seguintes obras: ALEXY, Robert. Teoria de los derechos fundamentales. Madrid: Centro de Estudios Constitucionales, 1993; ANDRADE, José Carlos Vieira de. Os direitos fundamentais na Constituição portuguesa de 1976. Coimbra: Almedina, 1998; SARLET, Ingo Wolfgang. A eficácia dos direitos fundamentais. 9. ed. Porto Alegre: Livraria do Advogado, 2007. 
A concretização dos direitos sociais e o controle jurisdicional de políticas públicas exigem, certamente, um profundo redimensionamento do papel do Direito e das instituições jurídico-democráticas. Aquele modelo jurídico de cunho marcadamente liberal (Estado liberal de direito) ${ }^{8}$, no mais das vezes indiferente às pressões das massas populares e às lutas pelo direito a ter direitos, deve ser suplantado por um modelo de "Estado de direito inclusivo", que assume obrigações perante os cidadãos e procura dialogar com os anseios dos mais diferentes conjuntos de atores sociais, aqui nomeado de Estado constitucional de direito.

Esse modelo de Estado de direito inclusivo (Estado constitucional de direito) vem acompanhado de um sofisticado marco teórico, que pretende a superação das teorias do positivismo jurídico e a consolidação de uma nova teoria da Constituição (neoconstitucionalismo). Por certo, não se pode desvincular as mudanças teóricas que respaldaram a passagem do positivismo jurídico para o pós-positivismo ou neoconstitucionalismo, das profundas mudanças sociais e econômicas evidenciadas no curso do Século XX.

O positivismo jurídico, aqui entendido como aquela teoria jurídica que encara o direito positivo como o único objeto da "ciência jurídica" e que não admite conexão entre o Direito, a moral e a política, servia a um modelo de sociedade, o modelo liberal-individualista. Em uma sociedade marcada pela homoge-

8 A expressão "Estado liberal de direito" é utilizada pelo simples fato de ter sido consagrada pela ciência política, mesmo não sendo a mais coerente. Em última análise, o atual modelo de Estado também pode ser definido como liberal, já que garante inúmeros direitos individuais e, cada vez mais, diminui sua intervenção na economia, conduzindo-se à forma de Estado mínimo. Em verdade, dever-se-ia falar em "Estado legal", já que, com a derrocada do Estado absolutista e a ascensão do Estado de direito, houve, de fato, uma verdadeira substituição do império da vontade do monarca pelo império da vontade da lei, uma espécie de totem da racionalidade moderna. A lei passou a ser a vontade soberana, sob a qual se colocaram o Estado e os cidadãos. Para um estudo aprofundado acerca do Estado liberal e a passagem para o Estado social, pode-se consultar, entre outros: BONAVIDES, Paulo. Do Estado liberal ao Estado social. 6. ed. rev. e ampl. São Paulo: Malheiros, 1996; LUCAS VERDÚ, Pablo. Estado liberal de derecho y Estado social de derecho. Madrid: Universidad de Salamanca, 1955; PEREZ LUNÕ, Antonio Enrique. Derechos humanos, Estado de derecho y Constituición. 5. ed. Madrid: Tecnos, 1994. 
neidade política e igualdade formal jurídica, o sistema normativo que melhor garante a propriedade e a liberdade de mercado é, por certo, o sistema de regras. Ante a mudança do cenário social, a consolidação dos movimentos de classe, o fortalecimento de novos atores sociais, o pluralismo político e jurídico, a heterogeneidade política da sociedade, evidencia-se a necessidade de repensar as bases teóricas do Direito. Neste sentido, fala-se em neoconstitucionalismo ${ }^{9}$, entendido como uma teoria contemporânea que procura enfrentar os problemas da indeterminação do Direito, sustentando uma situação de estreita relação entre Direito, moral e política.

O neoconstitucionalismo não pode, por certo, ser encarado como uma proposta acabada de teoria do direito, com pretensões de sistematicidade e adequação. Na verdade, sob o rótulo ainda em construção do neoconstitucionalismo, reúnemse diversas doutrinas de teoria constitucional, por vezes até entre si contraditórias. Umas mais radicais e inconciliáveis até com os mais abertos modelos de "positivismo jurídico crítico" 10 , outras, porém, em larga medida conciliáveis com esses últimos. Por outro lado, em maior ou menor amplitude, todas essas doutrinas estão voltadas à consolidação de uma sólida teoria

9 Para um estudo mais aprofundado acerca do neoconstitucionalismo, pode-se consultar: CARBONELL, Miguel (Coord.). Neoconstitucionalismo(s). 2. ed. Madrid: Trotta, 2005; CARBONELL, Miguel (Coord.). Teoría del neoconstitucionalismo: ensaios escogidos. Madrid: trotta, 2007; SARMENTO, Daniel Antonio de Moraes. O neoconstitucionalismo no Brasil: riscos e possibilidades. In: LEITE, George Salomão; SARLET, Ingo Wolfgang (Org.). Direitos fundamentais e Estado Constitucional: estudos em homenagem a J. J. Gomes Canotilho. São Paulo; Coimbra: Revista dos Tribunais; Coimbra Editora, 2009, p. 09-49.

10 Sobre o positivismo jurídico crítico, pode-se estudar a teoria do garantismo jurídico do jurista italiano Luigi FERRAJOLI, que pode ser considerado um sofisticado modelo de positivismo jurídico crítico, que pretende a sólida limitação dos poderes públicos constituídos (Estado de direito) e efetiva defesa dos direitos fundamentais, mas sem incorrer nos graves déficits de legitimidade e indeterminação do ativismo judicial ponderacionista (argumentação de princípios). Para um estudo aprofundado do garantismo jurídico: CARBONELL, Miguel; SALAZAR, Pedro (Coord.). Garantismo: estudios sobre el pensamiento jurídico de Luigi Ferrajoli. Madrid: Trotta, 2005; CADEMARTORI, 2007, passim; FERRAJOLI, Luigi. Garantismo: una discusión sobre derecho y democracia. Madrid: Trotta, 2006; FERRAJOLI, Luigi. Derecho y razón: teoría del garantismo penal. 4. ed. Madrid: Trotta, 2000; FERRAJOLI, Luigi. Principia iuris: teoria del diritto e della democrazia. Roma: Laterza, 2007. 
da supremacia da Constituição, da defesa da força normativa dos princípios constitucionais, da eficácia dos direitos fundamentais, da interpretação conforme a Constituição e do reconhecimento do Judiciário como instância de concretização dos direitos fundamentais.

A Constituição de 1988 está inserida nesse contexto: uma carta política que, embora taxada de prolixa, reflete os interesses das mais diversas camadas da sociedade brasileira. A expressiva gama de direitos fundamentais de cunho liberal e social é um forte indicativo neste sentido. $O$ grande desafio está na sua efetivação, sobretudo os direitos sociais (aqueles direitos fundamentais ditos positivos), que exigem a atuação direta e efetiva do Poder Público.

A supremacia da Constituição e o caráter vinculante dos direitos fundamentais são dois traços característicos fundantes do Estado constitucional de direito, um modelo de Estado de direito pautado pela força normativa dos princípios constitucionais ${ }^{11}$ e pela pretensão de consolidação de um modelo de justiça substancial ${ }^{12}$.

Seguindo o estudo da temática proposta, passar-se-á a uma prévia análise da categoria "políticas públicas", para em seguida avançar ao exame da concretização dos direitos sociais e o controle jurisdicional de políticas públicas.

11 O estudo mais aprofundado acerca da teoria dos princípios constitucionais pode ser buscado em: ÁVILA, Humberto. Teoria dos princípios: da definição à aplicação dos princípios jurídicos. 4. ed. São Paulo: Malheiros, 2004; BONAVIDES, Paulo. Curso de Direito Constitucional. 10. ed. São Paulo: Malheiros, 2000; CRISTÓVAM, José Sérgio da Silva. Colisões entre princípios constitucionais: razoabilidade, proporcionalidade e argumentação jurídica. 1. ed. 4. tir. Curitiba: Juruá, 2011; ESPINDOLA, Ruy Samuel. Conceito de princípios constitucionais: elementos teóricos para uma formulação dogmática constitucionalmente adequada. 2. ed. São Paulo: Revista dos Tribunais, 2002.

12 Debatendo acerca desse novo modelo de Estado de direito, o constitucionalista Paulo BONAVIDES ensina que, "com a queda do positivismo e o advento da teoria material da Constituição, o centro de gravidade dos estudos constitucionais, que dantes ficava na parte organizacional da Lei Magna - separação de poderes e distribuição de competências, enquanto forma jurídica de neutralidade aparente, típica do constitucionalismo do Estado Liberal - se transportou para a parte substantiva, de fundo e conteúdo, que entende com os direitos fundamentais e as garantias processuais da liberdade, sob a égide do Estado social". BONAVIDES, 2000 , p. 584. 


\section{A ANÁLISE JURÍDICA DA CATEGORIA "POLÍTICAS PÚBLICAS"}

O interesse jurídico pelas políticas públicas vem crescendo em simetria com o agigantamento do Poder Executivo, fenômeno próprio do Estado social de direito ${ }^{13}$. Justifica, e até impõe, o reexame e o redimensionamento da classificação tradicional dos poderes estatais, baseada na supremacia do Poder Legislativo e no papel secundário do Poder Executivo, deslocando o lugar de destaque da lei para as políticas públicas, ou seja, do Estado legislativo para o Estado social, que tem na realização de finalidades coletivas a sua principal fonte de legitimidade ${ }^{14}$.

Pode-se dizer que as políticas públicas representam os instrumentos de ação dos governos, numa clara substituição dos "governos por leis" (government by law) pelos "governos

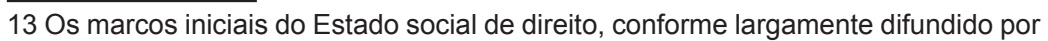
historiadores e estudiosos da ciência política, são as constituições mexicana de 1917 e alemã de 1919 (Constituição de Weimar). Entretanto, a evolução do modelo estatal intervencionista, com o reconhecimento normativo dos direitos sociais, pode ser notada na Alemanha desde a segunda metade do século XIX, em concomitância com a crise do modelo liberal-individualista de Estado. Assim, pode-se adotar como termo inicial do Estado social, ainda que sob um prisma muito mais formal que substancial, o governo do Kaiser prussiano Otto Von Bismarck. Cabe ressaltar, por outro lado, que durante o século XIX o papel constitucional dos direitos sociais se resumia ao de meras cláusulas políticas de compromisso, no mais das vezes promovidas por elites conservadoras ou liberais reformistas que pretendiam legitimar o Estado liberal, caracterizado pelo baixo intervencionismo para a contensão das desigualdades sociais, na tentativa de desarticular os movimentos sociais que buscavam um reconhecimento mais amplo de seus interesses. Exemplo paradigmático desse momento histórico é justamente o Estado social autoritário de Bismarck, onde os direitos sociais refletiam verdadeiras concessões outorgadas ex principis por oportunismo político e na intenção de neutralizar as crescentes demandas sociais, muito longe de se constituírem em verdadeiras conquistas decorrentes dos movimentos sociais organizados. Para um estudo mais aprofundado acerca da evolução do Estado social e da efetivação dos direitos sociais, pode-se consultar: PISARELLO, Geraldo. Del Estado social legislativo al Estado social constitucional: por una protección compleja de los derechos sociales. Revista de Teoría y Filosofía del Derecho, n. ${ }^{\circ} 15$, Alicante: Isonomia, 2001, p. 81-107.

14 Segundo Fábio Konder COMPARATO, o autor pioneiro nesta reclassificação das funções do Estado foi Karl Loewenstein, para quem a nova tripartição dos poderes é a de policy determination, policy execution e policy control, com a substituição da lei pela política pública, mantendo-se a mesma separação entre a declaração, a execução e o juízo de revisão. COMPARATO, Fábio Konder. Ensaio sobre o juízo de constitucionalidade de políticas públicas. Revista dos Tribunais, ano 86, n. 737, março, São Paulo, 1997, p. 17. 
por políticas" (government by policies) ${ }^{15}$. $\bigcirc$ fundamento mediato e fonte de justificação das políticas públicas é o Estado social, marcado pela obrigação de efetivação dos direitos fundamentais positivos, aqueles que exigem uma prestação positiva do Poder Público (BUCCI, 1996, p. 135).

Há uma questão que deve ser analisada previamente à definição de política pública: a política não é norma nem ato jurídico; no entanto, as normas e atos jurídicos são componentes da mesma, uma vez que esta pode ser entendida como "um conjunto organizado de normas e atos tendentes à realização de um objetivo determinado". As normas, decisões e atos que integram a política pública têm na finalidade da política seus parâmetros de unidade. Isoladamente, as decisões ou normas que a compõem são de natureza heterogênea e submetem-se a um regime jurídico próprio (COMPARATO, 1997, p. 18).

No entendimento de COMPARATO, as políticas públicas são programas de ação governamental. $\mathrm{O}$ autor segue a posição doutrinária de Ronald DWORKIN, para quem a política (policy), contraposta à noção de princípio, designa aquela espécie de padrão de conduta (standard) que assinala uma meta a alcançar, no mais das vezes uma melhoria das condições econômicas, políticas ou sociais da comunidade, ainda que certas metas sejam negativas, por implicarem na proteção de determinada característica da comunidade contra uma mudança hostil ${ }^{16}$.

Segundo defende Maria Paula Dallari BUCCI, há certa proximidade entre as noções de política pública e de plano,

150 debate acerca da categoria "políticas públicas" e seu controle judicial já foi iniciado alhures, sendo aqui ampliado para a análise de jurisprudência. Neste sentido, pode-se consultar: CRISTÓVAM, José Sérgio da Silva. Considerações acerca do controle jurisdicional de políticas públicas. In: ABREU, Pedro Manoel; OLIVEIRA, Pedro Miranda de (Org.). Direito e processo: estudos em homenagem ao Desembargador Norberto Ungaretti. Florianópolis: Conceito Editorial, 2007, v. 01, p. 233-250.

16 Nas palavras de DWORKIN: "Los argumentos de principio se proponen establecer um derecho individual; los argumentos políticos se proponen establecer um objetivo colectivo. Los principios son proposiciones que describen derechos; las políticas son proposiciones que describen objetivos". DWORKIN, Ronald. Los derechos en serio. Traducción de Marta Guastavino. 2. ed. Barcelona: Ariel Derecho, 1989, p. 158 e ss. 
embora aquela possa consistir num programa de ação governamental veiculado por instrumento jurídico diverso do plano. "A política é mais ampla que o plano e define-se como o processo de escolha dos meios para a realização dos objetivos do governo, com a participação dos agentes públicos e privados. [...] A política pública transcende os instrumentos normativos do plano ou do programa. Há, no entanto, um paralelo evidente entre o processo de formulação da política e a atividade de planejamento" (BUCCI, 2002, p. 259).

Desta forma, BUCCI define políticas públicas como "programas de ação governamental visando a coordenar os meios à disposição do Estado e as atividades privadas, para a realização de objetivos socialmente relevantes e politicamente determinados" (BUCCI, 2002, p. 241).

As políticas públicas podem ser entendidas como o conjunto de planos e programas de ação governamental voltados à intervenção no domínio social, por meio dos quais são traçadas as diretrizes e metas a serem fomentadas pelo Estado, sobretudo na concretização dos objetivos e direitos fundamentais insculpidos na Constituição.

Há que se fazer, ainda, a distinção entre política pública e política de governo, uma vez que enquanto esta guarda profunda relação com um mandato eletivo, aquela, no mais das vezes, pode atravessar vários mandatos. Deve-se reconhecer, por outro lado, que o cenário político brasileiro demonstra que é comum a confusão entre essas duas categorias. A cada eleição, principalmente quando ocorre alternância de partidos, grande parte das políticas públicas fomentadas pela gestão que deixa o poder é abandonada pela gestão que o assume.

Inegável, por certo, que a análise jurídica das políticas públicas marca profundamente a evolução do Direito como um todo, acompanhando a consolidação do chamado Estado democrático de direito, o Estado constitucional pautado pela defesa dos direitos de liberdade e pela implementação dos direitos sociais. 
No Estado constitucional de direito, a função fundamental da Administração Pública é a concretização dos direitos fundamentais positivos, por meio de políticas públicas gestadas no seio do Poder Legislativo ou pela própria Administração ${ }^{17}$, políticas estas orientadas pelos princípios e regras dispostos na Constituição.

Independentemente do espaço de poder onde são geradas, se no Poder Legislativo - discutindo e aprovando as leis, os planos e os orçamentos necessários a sua efetivação - ou na Administração Pública, impende concluir que as políticas públicas são atividades marcadamente administrativas e submetidas ao regime jurídico administrativo. As funções de planejar, governar, gerir e direcionar os recursos financeiros são próprias da Administração Pública.

Um dos principais problemas que se colocam quando do estudo da consecução de políticas públicas é a possibilidade do controle jurisdicional. Até que ponto e sob quais parâmetros é possível a revisão judicial acerca da legalidade e constitucionalidade da ação ou (sobretudo) omissão do Poder Público na concretização de políticas públicas? A resposta a este problema tentar-se-á esboçar a seguir.

\section{O DEBATE TEÓRICO ACERCA DO CONTROLE JURISDICIONAL DE POLÍTICAS PÚBLICAS}

Uma primeira questão que deve ser discutida, no que toca à justiciabilidade de políticas públicas ${ }^{18}$, refere-se à diferença

17 Segundo constata BUCCI, a exteriorização das políticas públicas se afasta de um padrão uniforme e claramente apreensível pelo ordenamento jurídico. Por vezes, podem ser instituídas por leis, como a Política Nacional de Recursos Hídricos - Lei n. 9.433/97; outras vezes, são consubstanciadas em emendas constitucionais, como no caso do Fundo de Manutenção e Desenvolvimento do Ensino Fundamental e de Valorização do Magistério - FUNDEF, criado pela Emenda Constitucional n. 14/96 e sucedido, mais recentemente, pelo Fundo de Manutenção e Desenvolvimento da Educação Básica e de Valorização dos Profissionais de Educação - FUNDEB, criado pela Emenda Constitucional n. 53/06; em outros casos, podem ainda decorrer de atos administrativos isolados ou ordenados em programas, como as políticas de transporte municipal. Idem, p. 257.

$18 \mathrm{Na}$ literatura jurídica latino-americana, para uma análise extremamente abalizada acerca da concretização dos direitos sociais, pode-se consultar: ABRAMOVICH, 
entre o juízo de validade de uma política governamental e o juízo de validade das normas e atos que a compõem. Conforme sustenta COMPARATO, uma lei, "editada no quadro de determinada política pública, por exemplo, pode ser inconstitucional, sem que esta última o seja. Inversamente, determinada política governamental, em razão da finalidade por ela perseguida, pode ser julgada incompatível com os objetivos constitucionais que vinculam a ação do Estado, sem que nenhum dos atos administrativos, ou nenhuma das normas que a regem, sejam, em si mesmos, inconstitucionais" (COMPARATO, 1997, p. 18-19).

Neste sentido, mostra-se necessária uma ampliação do juízo de constitucionalidade das leis e atos do Poder Público para alcançar as políticas públicas. Em um Estado constitucional como o brasileiro, marcado por uma Constituição de inegável feição dirigente, os objetivos e direitos fundamentais inscritos, expressa ou implicitamente, no texto constitucional, são juridicamente vinculantes para todos os poderes estatais.

Não se pode, por certo, afastar a judicialização das políticas públicas, sob o argumento simplista de que consubstanciam questões exclusivamente políticas. As políticas públicas têm inegáveis contornos jurídicos, havendo um verdadeiro poder-dever do Judiciário em analisar sua legalidade e constitucionalidade.

A já quase centenária Constituição de 1934 trazia, em seu artigo 68, disposição que expressamente vedava "ao Poder Judiciário conhecer de questões exclusivamente políticas". Ainda que a Constituição de 1988 não albergue dispositivo semelhante, impende reconhecer que, mesmo no seio daquela Constituição, não estava vedado o juízo acerca da constitucionalidade de políticas públicas. A vedação se limitava às questões exclusivamente políticas, não aos programas de ação governamental.

Por questões exclusivamente políticas há que se entender, por exemplo, a declaração de guerra, a celebração da paz, a

Víctor; COURTIS, Christian. Los derechos sociales como derechos exigibles. Madrid: Editorial Trotta, 2002. 
decretação de estado de defesa e de estado de sítio, nomeação e exoneração de Ministros de Estado, etc. São questões dessa natureza que podem ser caracterizadas como exclusivamente políticas, refugindo ao controle jurisdicional.

Do ponto de vista teórico, o controle jurisdicional de políticas públicas vem sendo discutido no âmbito de duas correntes contrapostas: a corrente procedimentalista, ancorada principalmente nas idéias de Jürgen HABERMAS; e a corrente substancialista, que busca sustentação no pensamento jurídico e político de DWORKIN (VIANNA, 1999, p. 155 e ss.).

No entendimento da corrente procedimentalista, o juízo de constitucionalidade de políticas públicas acaba por dificultar o exercício da cidadania participativa, favorecendo a desagregação social e o individualismo. $\mathrm{O}$ cidadão, colocando-se na posição de simples sujeito de direitos, assume uma posição passiva perante o Estado, uma espécie de cidadão-cliente, frente ao Judiciário fornecedor de serviços.

O fortalecimento da cidadania ativa é potencializado por meio da conquista de canais de comunicação, que veiculam o poder democrático do centro para a periferia. Deste modo, o papel da Constituição é assegurar a existência desses canais ou procedimentos de ação comunicativa dos cidadãos, para que os mesmos criem seu próprio direito, uma vez que a lei não pode ser vista como a vontade direta do povo. A Constituição não deve expressar conteúdos substantivos, mas apenas instrumentalizar os direitos de participação e comunicação democrática (democracia deliberativa) (HABERMAS, 1997, p. 09 e ss.).

Uma das mais lúcidas críticas endereçadas ao modelo de democracia procedimental defendido por HABERMAS é a exigência de uma prévia cultura política da liberdade, de base social estável, capaz de produzir consenso democraticamente. Outra exigência da democracia procedimental é a existência de partidos políticos fortes e distantes das ingerências econômicas, o que acaba por distanciar o modelo da atual conjuntura social, principalmente de países como o Brasil, onde a cultura 
da democracia ativa e da cidadania participativa está apenas engatinhando.

A corrente substancialista, por seu turno, defende que o Estado constitucional exige uma redefinição do papel do Poder Judiciário, porquanto, com a evolução do Estado das leis para o Estado das políticas públicas, resta ao Judiciário a função de assegurar a concretização dos direitos fundamentais e a progressiva marcha da sociedade para um ideal de justiça substancial.

A judicialização das políticas públicas encontra seu fundamento na supremacia da Constituição, norma de caráter fundamental e superior a todos os poderes estatais. Ao efetuar o juízo de constitucionalidade de políticas públicas, o Judiciário acaba por desempenhar sua função precípua, qual seja: garantir a prevalência da Constituição.

Há que se refutar, ainda, o argumento da corrente procedimentalista, para a qual a justiciabilidade do Poder Público acaba por tolher a democracia participativa, transformando os cidadãos em clientes do Estado paternalista. Em verdade, o Poder Judiciário transforma-se em instância de efetivação da cidadania participativa, um canal aberto aos cidadãos para pleitearem a consecução de ações governamentais voltadas à efetivação dos direitos sociais.

Procurando estabelecer uma síntese da relação entre as duas correntes, aparentemente contrapostas, Eduardo APPIO defende que a "formulação das políticas públicas depende, portanto, de uma concepção procedimental de democracia, enquanto que o controle judicial de sua execução demanda uma concepção substancial, atrelada ao principio da isonomia" (APPIO, 2008, p. 259).

Embora na doutrina a teoria da justiciabilidade das políticas públicas esteja sedimentada a mais tempo, no âmbito jurisprudencial sua aceitação é bem mais recente ${ }^{19}$, sendo que, até

19 No sentido da vedação do controle judicial de políticas públicas: Recurso Especial n. 63.128, Rel. Min. Adhemar MACIEL, Sexta Turma, julgado em 11 de março de 1996; Recurso Especial n. 169.876, Rel. Min. José DELGADO, Primeira Turma, julgado em 16 de junho de 1998. Disponível em: <http: //www.stj.jus.br>. Acesso em: 08 set. 2010. 
o início deste século, reinava firme o entendimento de que o princípio da separação de poderes constituía-se em obstáculo intransponível ao juízo de constitucionalidade de políticas públicas $^{20}$.

Somente no início do Século XXI começaram a surgir os primeiros precedentes dissonantes da então jurisprudência dominante, como o julgado da Segunda Câmara Cível do Tribunal de Justiça de São Paulo, citado por BUCCI, em Apelação Cível em Ação Civil Pública, promovida pelo Ministério Público paulista, com o objetivo de obrigar determinando ente municipal à construção de sistema de saneamento básico. Segundo o Tribunal de Justiça paulista a "saúde coletiva é, por sua natureza, prioritária; a respeito, não há discricionariedade do Poder Público: sem água cujos padrões de pureza se encontrem dentro das classes legais de aproveitamento [...] a própria vida não é possível, como bem primeiro!” (BUCCI, 2002, p. 275).

Alinhadas algumas considerações teóricas acerca da justiciabilidade de políticas públicas, passar-se-á agora à análise de alguns argumentos contrários à possibilidade de atuação/intervenção do Poder Judiciário na concretização dos direitos sociais (princípio da separação de poderes, limites orçamentários e reserva do possível), a partir do entendimento da jurisprudência nacional sobre o tema.

\section{A JUSTICIABILIDADE DE POLÍTICAS PÚBLICAS NA JURISPRUDÊNCIA: SEPARAÇÃO DE PODERES, LIMITES ORÇAMENTÁRIOS E RESERVA DO POSSÍVEL}

A Constituição é a baliza mestra da atuação do Poder Público. Vincula toda a ação do Estado e exige que esteja voltada ao implemento de suas disposições. O Estado colocase perante a Constituição como instrumento de realização dos

20 Sobre a análise do princípio da separação de poderes e a justiciabilidade de políticas públicas, pode-se consultar, entre outros: CRISTÓVAM, 2007, p. 242 e ss. 
ditames constitucionais. Este é o verdadeiro fundamento de sua existência, sua fonte de legitimidade.

Não se pode aceitar, portanto, que o cumprimento da Constituição seja preterido pela observância de uma norma infraconstitucional, ou por um quadro de conjuntura políticoeconômica desfavorável. A Constituição ostenta força normativa, ativa e vinculante, exigindo a máxima atuação dos poderes constituídos para o seu fiel implemento. São inaceitáveis certas práticas governamentais que esquecem de cumprir a Constituição sob o argumento da falência orçamentária ${ }^{21}$ do Estado ou para garantir o cumprimento da Lei de Responsabilidade Fiscal.

Isoladamente, a escassez orçamentária não é argumento sólido o bastante para afastar o imperativo de implementação dos direitos fundamentais sociais. Ainda que os recursos públicos sejam limitados, não é vedado ao Judiciário determinar ao Estado a alocação de verbas orçamentárias específicas para o cumprimento de direitos sociais.

Nesse contexto, precedente de suma relevância refere-se ao controle jurisdicional de políticas públicas do direito fundamental à saúde e à higidez ambiental, no caso da concretização de adequado sistema de tratamento de esgoto, em uma determinada área da Praia de Canasvieiras, Município de Florianópolis (Santa Catarina). A Ação Civil Pública foi proposta pela Associação de Moradores de Canasvieiras e pelo Ministério Público Federal, contra o Município de Florianópolis, a Fundação Nacional de Saúde (FUNASA) e Companhia Catarinense de

21 Conforme dispõem os artigos 165 e seguintes da Constituição de 1988, o orçamento é composto por três leis orçamentárias, todas de iniciativa privativa do chefe do Poder Executivo, quais sejam: o plano plurianual, que estabelece as diretrizes, objetivos e metas da Administração Pública federal para as despesas de capital, outras delas decorrentes e para os programas de duração continuada; a lei de diretrizes orçamentárias, que compreende as metas e prioridades da Administração Pública federal, incluindo as despesas de capital para o exercício subseqüente, bem como, orienta a elaboração da lei orçamentária anual, dispõe acerca de alterações na legislação tributária e estabelece a política de aplicação das agências financeiras oficiais de fomento; e, a lei orçamentária anual, que trata da previsão de receita e fixação de despesa, do orçamento fiscal dos poderes da União, do orçamento de investimento das empresas em que a União detenha a maioria do capital social com direito a voto e do orçamento da seguridade social. 
Água e Saneamento (CASAN). A sentença, julgando totalmente procedente a ação, condenou solidariamente os réus à obrigação de fazer (construção da rede de saneamento), assinalando o prazo de 01 (um) ano para a execução das obras, conforme cronograma previamente oferecido pelos réus ${ }^{22}$.

Eis as precisas palavras do Juiz Federal Zenildo BODNAR: "Na aplicação do direito na modernidade tardia em que se vive, não pode o intérprete deixar de considerar a multiplicidade de relações que envolvem o funcionamento do Estado Contemporâneo, as suas carências e limitações e a sua função primordial que é fomentar o pleno desenvolvimento humano".

E complementa o julgador: "A interpretação que é necessariamente histórica, contextual e criativa, não pode ser e de fato não é um 'labor descompromissado', no qual se resolve a vida das pessoas apenas com trocadilhos de palavras. Também não poder representar um ato de rebeldia contra o Estado como se este fosse o único responsável por todas as mazelas existentes na sociedade".

Como sustenta BODNAR, "o controle jurisdicional da correção das políticas públicas na área da saúde e do meio ambiente é um dever do Poder Judiciário. Dever este que deve ser exercido na perspectiva intervencionista e transformadora para a emancipação do homem na sociedade, para o seu pleno desenvolvimento humano e para a consolidação da justiça social".

Por fim, advertindo acerca dos limites ao controle jurisdicional de políticas públicas, o Juiz Federal BODNAR defende que:

(...) a atuação/intervenção do Poder Judiciário somente será legítima na execução e na avaliação das políticas públicas ambientais e de saúde em

22 Ação Civil Pública n. 2004.72.00.017675-8, da Justiça Federal de Florianópolis (SC). Julgada em 29.03.2007, pelo Juiz Federal Zenildo BODNAR. Sentença confirmada integralmente, em grau de apelação, pelo Egrégio Tribunal Regional Federal da $4^{a}$ Região, em 26.08.2009, em acórdão da lavra da Desembargadora Federal Marga Inge Barth TESSLER. Disponível em: <http: //www.trf4.gov.br>. Acesso em: 08 set. 2010. 
função da forma de positivação constitucional destes direitos fundamentais conferindo densidade normativa suficiente para a sua concretização independentemente da superveniência de interposição legislativa. Entretanto, convém salientar que falta legitimidade constitucional para o Poder Judiciário formular políticas públicas ambientais e de saúde, as quais devem necessariamente observar critérios técnicos científicos e as opções democráticas canalizadas pelas vias institucionais adequadas.

No Superior Tribunal de Justiça, o debate acerca do controle jurisdicional de políticas públicas vem sendo cada vez mais recorrente, com a construção de uma jurisprudência forjada sob uma sofisticada matriz teórica de concretização dos direitos fundamentais. Neste sentido, o abalizado precedente relacionado ao direito fundamental à saúde, na decisão da Segunda Turma do STJ, no Recurso Especial n. 1041197 - MS, em acórdão da lavra do Ministro Humberto MARTINS²3, assim ementado:

ADMINISTRATIVO - AÇÃO CIVIL PÚBLICA - CONTROLE JUDICIAL DE POLÍTICAS PÚBLICAS - POSSIBILIDADE EM CASOS EXCEPCIONAIS - DIREITO À SAÚDE FORNECIMENTO DE EQUIPAMENTOS A HOSPITAL UNIVERSITÁRIO - MANIFESTA NECESSIDADE - OBRIGAÇÃO DO ESTADO - AUSÊNCIA DE VIOLAC̣ÃO DO PRINCÍPIO DA SEPARAÇÃO DOS PODERES - NÃOOPONIBILIDADE DA RESERVA DO POSSÍVEL AO MÍNIMO EXISTENCIAL. (...)

3. A partir da consolidação constitucional dos direitos sociais, a função estatal foi profundamente modificada, deixando de ser eminentemente legisladora em pró das liberdades públicas, para se tornar mais ativa com a missão de transformar a

23 Recurso Especial n. 1041197 - MS, da Segunda Turma do STJ. Julgado em 25.08.2009, em acórdão da lavra do Ministro Humberto MARTINS. Publicado no DJ em 16.09.2009. Disponível em: <http: //www.stj.jus.br>. Acesso em: 08 set. 2010. 
realidade social. Em decorrência, não só a administração pública recebeu a incumbência de criar e implementar políticas públicas necessárias à satisfação dos fins constitucionalmente delineados, como também, o Poder Judiciário teve sua margem de atuação ampliada, como forma de fiscalizar e velar pelo fiel cumprimento dos objetivos constitucionais.

4. Seria uma distorção pensar que o princípio da separação dos poderes, originalmente concebido com o escopo de garantia dos direitos fundamentais, pudesse ser utilizado justamente como óbice à realização dos direitos sociais, igualmente fundamentais. Com efeito, a correta interpretação do referido princípio, em matéria de políticas públicas, deve ser a de utilizá-lo apenas para limitar a atuação do judiciário quando a administração pública atua dentro dos limites concedidos pela lei. Em casos excepcionais, quando a administração extrapola os limites da competência que lhe fora atribuída e age sem razão, ou fugindo da finalidade a qual estava vinculada, autorizado se encontra o Poder Judiciário a corrigir tal distorção restaurando a ordem jurídica violada. (grifou-se)

Quando provocado, o Judiciário pode e deve garantir o cumprimento dos direitos fundamentais sociais, sem que isso possa configurar afronta ao princípio da separação de poderes ou trazer desequilíbrio ao orçamento do Estado. Levando em conta as circunstâncias do caso concreto, cabe ao juiz assinalar ao Poder Público um prazo razoável para o cumprimento da obrigação constitucional, sem que restem afetados os programas governamentais traçados nas leis orçamentárias.

Discutindo acerca do redimensionamento do princípio da separação de poderes, o constitucionalista italiano Riccardo GUASTINI ensina que no modelo de separação de poderes, "os juízes não podem controlar a legalidade dos atos do executivo, nem anular ou privá-los de eficácia (o controle da legalidade sobre atos da administração é atribuído aos órgãos internos da 
própria Administração). Ao contrário, no modelo de balanceamento de poderes, os atos do executivo são sujeitos a controle jurisdicional de legalidade, e os atos administrativos ilegais podem ser anulados (ou, ao menos, não aplicados) pelo juiz" (GUASTINI, 2001, p. 26).

Voltando ao citado precedente do STJ (Recurso Especial n. 1041197 - MS), no acórdão da lavra do Ministro Humberto MARTINS, retira-se a seguinte lição:

(...) 5 . O indivíduo não pode exigir do estado prestações supérfluas, pois isto escaparia do limite do razoável, não sendo exigivel que a sociedade arque com esse ônus. Eis a correta compreensão do princípio da reserva do possível, tal como foi formulado pela jurisprudência germânica. Por outro lado, qualquer pleito que vise a fomentar uma existência minimamente decente não pode ser encarado como sem motivos, pois garantir a dignidade humana é um dos objetivos principais do Estado Democrático de Direito. Por este motivo, o princípio da reserva do possível não pode ser oposto ao princípio do mínimo existencial.

6. Assegurar um mínimo de dignidade humana por meio de serviços públicos essenciais, dentre os quais a educação e a saúde, é escopo da República Federativa do Brasil que não pode ser condicionado à conveniência política do administrador público. A omissão injustificada da administração em efetivar as políticas públicas constitucionalmente definidas e essenciais para a promoção da dignidade humana não deve ser assistida passivamente pelo Poder Judiciário (...). (grifou-se)

O precedente do STJ, acerca do limite do razoável na concretização dos direitos sociais, mostra-se totalmente afinada com a doutrina de Robert ALEXY. Para tentar resolver o problema da escassez de recursos e o cumprimento de direitos fundamentais positivos, ALEXY propõe a aplicação do método 
de ponderação ${ }^{24}$, pelo qual a prestação pleiteada pelos cidadãos deve estar cingida àquilo que se pode razoavelmente exigir do Poder Público. Ainda que existam recursos, o limite do razoável veda aos cidadãos exigirem do Estado aquilo que possam prover como seus próprios recursos. Entretanto, segundo o autor impende reconhecer que o direito a um mínimo vital, à educação escolar, à assistência médica, à formação profissional, deve ter a efetivação garantida pelo Poder Público, por conta de que é mínimo o conflito com os demais princípios constitucionais (ALEXY, 1993, p. 494-499).

A prévia adequação do cumprimento de obrigações constitucionais às disponibilidades orçamentárias, com base em ampla prova técnica, resguarda o equilíbrio das finanças públicas sem descuidar da efetivação dos direitos sociais. $\mathrm{O}$ problema orçamentário e os limites da reserva do possível podem ser resolvidos por um ativismo judicial cauteloso, responsável e comprometido com a guarda da Constituição.

Outro argumento contrário à justiciabilidade de políticas públicas é a competência do Poder Legislativo para a destinação dos recursos públicos, mediante a aprovação das leis orçamentárias. Insustentável tal argumentação: a uma, porque o Legislativo não dispõe de competência absoluta para a destinação das verbas orçamentárias; a duas, porque o Legislativo está vinculado aos mandamentos constitucionais, sendo que a ausência de políticas públicas voltadas à implementação dos direitos fundamentais positivos exige o controle jurisdicional, até para resguardar o caráter normativo e vinculante da Constituição.

No Supremo Tribunal Federal, o debate acerca do controle jurisdicional de políticas públicas vem se mostrando recorrente e acirrado nos últimos anos. Neste sentido, acerca da concretização do direito fundamental à educação, a decisão da Segunda Turma do STF, no Agravo Regimental no Recurso

24 Para uma análise do princípio da ponderação e da teoria dos princípios em Robert ALEXY, pode-se consultar: CRISTÓVAM, 2011, passim. 


\section{Extraordinário n. 410715 - SP, em acórdão da lavra do Ministro Celso de MELLO $^{25}$, assim ementado ${ }^{26}$ :}

(...) A educação infantil representa prerrogativa constitucional indisponível, que, deferida às crianças, a estas assegura, para efeito de seu desenvolvimento integral, e como primeira etapa do processo de educação básica, o atendimento em creche e o acesso à pré-escola (CF, art. 208, IV). - Essa prerrogativa jurídica, em conseqüência, impõe, ao Estado, por efeito da alta significação social de que se reveste a educação infantil, a obrigação constitucional de criar condições objetivas que possibilitem, de maneira concreta, em favor das "crianças de zero a seis anos de idade" (CF, art. 208, IV), o efetivo acesso e atendimento em creches e unidades de pré-escola, sob pena de configurar-se inaceitável omissão governamental, apta a frustrar, injustamente, por inércia, o integral adimplemento, pelo Poder Público, de prestação estatal que lhe impôs o próprio texto da Constituição Federal. - A educação infantil, por qualificar-se como direito fundamental de toda criança, não se expõe, em seu processo de concretização, a avaliações meramente discricionárias da Administração Pública, nem se subordina a razões de puro pragmatismo governamental. (...) - Embora resida, primariamente, nos Poderes Legislativo e Executivo, a prerrogativa de formular e executar políticas públicas, revela-se possível, no entanto, ao Poder Judiciário, determinar, ainda que em bases excepcionais, especialmente nas hipóteses de políticas públicas definidas pela própria Constituição, sejam estas implementadas pelos órgãos estatais inadimplentes, cuja

25 Agravo Regimental no Recurso Extraordinário n. 410715 - SP, da Segunda Turma do STF. Julgado em 22.11.2005, em acórdão da lavra do Ministro Celso de MELLO. Publicado no DJ em 03.02.2006. Disponível em: <http: //www.stf.jus.br>. Acesso em: 08 set. 2010.

26 No mesmo sentido: Agravo Regimental no Recurso Extraordinário n. 595595 - SC, da Segunda Turma do STF. Julgado em 28.04.2009, em acórdão da lavra do Ministro Eros GRAU. Publicado no DJ em 28.05.2009; Agravo Regimental no Recurso Extraordinário n. 594018 - RJ, da Segunda Turma do STF. Julgado em 23.06.2009, em acórdão da lavra do Ministro Eros GRAU. Publicado no DJ em 06.08.2009. Disponível em: <http: //www.stf.jus.br>. Acesso em: 08 set. 2010. 
omissão - por importar em descumprimento dos encargos político-jurídicos que sobre eles incidem em caráter mandatório - mostra-se apta a comprometer a eficácia e a integridade de direitos sociais e culturais impregnados de estatura constitucional (...). (grifou-se)

O orçamento deve ser entendido como um instrumento de implementação das disposições constitucionais, a expressão do planejamento das políticas públicas a serem realizadas pela Administração Pública. Nele estão contidas a destinação das verbas, a estimativa das receitas e a fixação das despesas de determinado exercício financeiro. Trata-se de um conjunto de atos normativos pelos quais são elaborados, avaliados e executados os programas governamentais, em todos os planos de atuação do Poder Público.

Neste sentido, a Constituição vincula a elaboração e execução das leis orçamentárias, exigindo a previsão de programas e planos de ação governamental destinados à efetivação dos direitos fundamentais sociais. Não se pode mais encarar o orçamento como simples peça contábil de previsão de receita e fixação de despesa, mas sim como verdadeira expressão do planejamento estatal voltado ao desenvolvimento social e econômico.

No precedente acima lembrado, o voto do Ministro Celso de MELLO, com extremo acerto, enfrentou o conflito entre deficiência orçamentária e concretização dos direitos fundamentais, sobretudo os direitos de segunda geração, que impõe e exigem do Estado prestações positivas concretizadoras. Conforme restou assentado:

(...) a realização dos direitos econômicos, sociais e culturais - além de caracterizar-se pela gradualidade de seu processo de concretização - depende, em grande medida, de um inescapável vínculo financeiro subordinado às possibilidades orçamentárias do Estado, de tal modo que, comprovada, objetivamente, a incapacidade econômico-financeira da 
pessoa estatal, desta não se poderá razoavelmente exigir, considerada a limitação material referida, a imediata efetivação do comando fundado no texto da Carta Política.

Não se mostrará lícito, no entanto, ao Poder Público, em tal hipótese - mediante indevida manipulação de sua atividade financeira e/ou políticoadministrativa - criar obstáculo artificial que revele o ilegítimo, arbitrário e censurável propósito de fraudar, de frustrar e de inviabilizar o estabelecimento e a preservação, em favor da pessoa e dos cidadãos, de condições materiais mínimas de existência.

Cumpre advertir, desse modo, que a cláusula da 'reserva do possível' - ressalvada a ocorrência de justo motivo objetivamente aferível - não pode ser invocada, pelo Estado, com a finalidade de exonerar-se do cumprimento de suas obrigações constitucionais, notadamente quando, dessa conduta governamental negativa, puder resultar nulificação ou, até mesmo, aniquilação de direitos constitucionais impregnados de um sentido de essencial fundamentalidade. (grifou-se)

$\mathrm{Na}$ mesma linha, o constitucionalista Ingo Wolfgang SARLET denuncia que a reserva do possível tem sido utilizada entre nós, falaciosamente, "como argumento impeditivo da intervenção judicial e desculpa genérica para a omissão estatal no campo da efetivação dos direitos fundamentais, principalmente de cunho social. Assim, levar a serio a reserva do possível (e ela deve ser levada a sério, embora sempre com as devidas reservas) significa também, especialmente em face do sentido disposto no artigo $5^{\circ}, \S 1^{\circ}$ da Constituição Federal, que cabe ao poder público o ônus da comprovação efetiva da indisponibilidade total ou parcial de recursos e do não desperdício dos recursos existentes" (SARLET, 2007, p. 357).

A realização material dos direitos sociais constitucionalmente assegurados requer a destinação de elevada monta finan- 
ceira. A conhecida escassez de recursos públicos, sobretudo em Estados periféricos como o brasileiro, traz o problema da definição sobre quais políticas públicas devem ser concretizadas, já que a limitação orçamentária não comportaria o cumprimento dos direitos sociais na sua integralidade.

Mais recentemente, acerca da concretização de políticas públicas na área de segurança pública, o Agravo Regimental no Recurso Extraordinário n. 367432 - PR, em acórdão da lavra do Ministro Eros GRAU ${ }^{27}$, assim ementado:

AGRAVO REGIMENTAL NO RECURSO EXTRAORDINÁRIO. AÇÃO CIVIL PÚBLICA. SEGURANCAA PÚBLICA. LEGITIMIDADE. INTERVENÇÃO DO PODER JUDICIÁRIO. IMPLEMENTAÇÃO DE POLÍTICAS PÚBLICAS. OMISSÃO ADMINISTRATIVA. (...) 2. O Supremo fixou entendimento no sentido de que é função institucional do Poder Judiciário determinar a implantação de políticas públicas quando os órgãos estatais competentes, por descumprirem os encargos político-jurídicos que sobre eles incidem, vierem a comprometer, com tal comportamento, a eficácia e a integridade de direitos individuais e/ou coletivos impregnados de estatura constitucional, ainda que derivados de cláusulas revestidas de conteúdo programático (...). (grifou-se)

Por certo, em um Estado como o brasileiro, onde o déficit de políticas públicas para o implemento de direitos sociais alcança níveis absurdos, onde ainda está longe a realização material de direitos básicos, como níveis mínimos de assistência à saúde, educação fundamental, sistema de saneamento básico, etc., contrastando com um orçamento cada vez mais comprometido com o pagamento de serviços da dívida pública, sumamente espinhosa se mostra a discussão sobre a justiciabilidade de políticas públicas.

27 Agravo Regimental no Recurso Extraordinário n. 367432 - PR, da Segunda Turma do STF. Julgado em 20.04.2010, em acórdão da lavra do Ministro Eros GRAU. Publicado no DJ em 13.05.2010. Disponível em: <http: //www.stf.jus.br>. Acesso em: 08 set. 2010. 
Por outro lado, quanto maior é a escassez de recursos orçamentários, com maior responsabilidade deve ser feita sua destinação. Assim, SARLET sustenta o necessário aprimoramento dos mecanismos de gestão democrática dos recursos públicos e um efetivo ativismo judicial, que com cautela e responsabilidade deve zelar pela efetivação dos direitos fundamentais positivos (SARLET, 2007, p. 339 e ss.).

\section{CONCLUSÃO}

O estudo da concretização dos direitos sociais e o controle jurisdicional de políticas públicas, sugere, necessariamente, o estabelecimento de uma sólida teoria da Constituição. Toda a temática desenvolvida gravita no entorno de uma teoria da Constituição capaz de se sobrepor a conjunturas político-econômicas, e refundar uma ordem constitucional pautada na supremacia da Constituição, na força normativa e vinculante dos direitos fundamentais e na consolidação do Estado como instrumento de efetivação das normas constitucionais.

Sem a firme e viva radiação da ordem constitucional no lastro social, sem a consolidação de uma verdadeira "cultura da Constituição", torna-se difícil a efetiva justiciabilidade de políticas públicas. A participação ativa e efetiva da sociedade, por meio das mais diversas organizações sociais e, principalmente, do Ministério Público, é condição inarredável ao processo de educação constitucional.

Neste contexto, mostra-se crucial o papel do Poder Judiciário, enquanto guardião da ordem constitucional e conformador da ação administrativa e legislativa dos demais poderes constituídos. O ordenamento constitucional exige um Poder Judiciário imbuído de "vontade de Constituição", consciente de seu destacado mister na efetivação das normas constitucionais, que não se furte em decidir acerca da adequação das ações governamentais para o implemento dos direitos fundamentais.

Os objetivos e direitos fundamentais que orientam a Constituição gozam de plena força normativa, vinculando todos os 
poderes constituídos. O Estado constitucional e seus órgãos funcionalmente divididos buscam o fundamento de legitimidade na Constituição. Todos são instrumentos que devem estar à disposição da Constituição, voltados a sua fiel concretização.

Inafastável, portanto, a justiciabilidade de políticas públicas. Muito mais que um poder, o controle de políticas públicas é dever inarredável do Poder Judiciário, a quem compete fazer valer a vontade constitucional. Tal controle não afronta o princípio da separação de poderes, senão o fortalece e nele se justifica, porquanto a separação de poderes deve ser entendida como uma divisão de funções necessária a uma melhor satisfação dos ditames constitucionais.

Para a consolidação dos direitos fundamentais de liberdade e concretização dos direitos fundamentais sociais, urge a consolidação de um ativismo judicial responsável e consciente do lugar de destaque que o Poder Judiciário ocupa no Estado constitucional. $\mathrm{O}$ controle jurisdicional de políticas públicas exige um Judiciário forte e independente, capaz de garantir a supremacia da Constituição, ainda que em tempos de conjunturas político-econômicas desfavoráveis.

Embora as questões orçamentárias e a reserva do possivel representem graves problemas na implementação de políticas públicas voltadas ao desenvolvimento social, por certo, um dos maiores entraves à consolidação de um efetivo controle jurisdicional de políticas públicas está na insipiência dos mecanismos de participação popular nas decisões políticas, no difícil fortalecimento de uma democracia participativa e de uma cidadania ativa, consciente de seu papel e que exija do Poder Judiciário uma postura comprometida com a Constituição. Fomentar esta cultura de participação popular é também atribuição dos juristas! 


\begin{abstract}
The realization of social rights from the judicial review of public policies, has gained a very special relief from the establishment of a model constitutional state of law, founded on the satisfaction of fundamental rights. This is the central object of the present study, besides presenting the limits and possibilities of an effective judicial activism, committed to the satisfaction of social rights and legitimized by contemporary constitutional discourse. Aside from the highly theoretical aspects, including the proposal for a legal concept of "public policy", following the analysis of understanding by the courts on the issue giving the parameters of judicial review of public policies. Finally, the conclusion is defending the relevance of themes, including the consolidation of a culture of defending the Constitution.
\end{abstract}

Keywords: social rights. Judicial review. Public policy. State constitutional law.

\title{
6 REFERÊNCIAS
}

ABRAMOVICH, Víctor; COURTIS, Christian. Los derechos sociales como derechos exigibles. Madrid: Editorial Trotta, 2002.

ALEXY, Robert. Teoria de los derechos fundamentales. Madrid: Centro de Estudios Constitucionales, 1993.

ANDRADE, José Carlos Vieira de. Os direitos fundamentais na Constituição portuguesa de 1976. Coimbra: Almedina, 1998.

APPIO, Eduardo. Controle judicial das políticas públicas no Brasil. Curitiba: Juruá, 2008.

ÁVILA, Humberto. Teoria dos princípios: da definição à aplicação dos princípios jurídicos. 4. ed. São Paulo: Malheiros, 2004.

BONAVIDES, Paulo. Curso de Direito Constitucional. 10. ed. São Paulo: Malheiros, 2000. 
. Do Estado liberal ao Estado social. 6. ed. rev. e ampl. São Paulo: Malheiros, 1996.

BUCCI, Maria Paula Dallari. As políticas públicas e o Direito Administrativo. Revista Trimestral de Direito Público, n. 13, São Paulo: Malheiros, 1996.

. Direito Administrativo e políticas públicas. São Paulo: Saraiva, 2002.

CADEMARTORI, Sérgio. Estado de direito e legitimidade: uma abordagem garantista. 2. ed. Campinas (SP): Millennium, 2007.

CARBONELL, Miguel (Coord.). Neoconstitucionalismo(s). 2. ed. Madrid: Trotta, 2005.

. Teoría del neoconstitucionalismo: ensaios escogidos. Madrid: trotta, 2007.

CARBONELL, Miguel; SALAZAR, Pedro (Coord.). Garantismo: estudios sobre el pensamiento jurídico de Luigi Ferrajoli. Madrid: Trotta, 2005.

COMPARATO, Fábio Konder. Ensaio sobre o juízo de constitucionalidade de políticas públicas. Revista dos Tribunais, ano 86, n. 737, março, São Paulo, 1997.

CRISTÓVAM, José Sérgio da Silva. Colisões entre princípios constitucionais: razoabilidade, proporcionalidade e argumentação jurídica. 1. ed. 4. tir. Curitiba: Juruá, 2011.

. Considerações acerca do controle jurisdicional de políticas públicas. In: ABREU, Pedro Manoel; OLIVEIRA, Pedro Miranda de (Org.). Direito e processo: estudos em homenagem ao Desembargador Norberto Ungaretti. Florianópolis: Conceito Editorial, 2007, v. 01, p. 233-250.

DWORKIN, Ronald. Los derechos en serio. Traducción de Marta Guastavino. 2. ed. Barcelona: Ariel Derecho, 1989.

ESPÍNDOLA, Ruy Samuel. Conceito de princípios constitucionais: elementos teóricos para uma formulação dogmática constitucionalmente adequada. 2. ed. São Paulo: Revista dos Tribunais, 2002.

FERRAJOLI, Luigi. Garantismo: una discusión sobre derecho y democracia. Madrid: Trotta, 2006. 2000. . Derecho y razón: teoría del garantismo penal. 4. ed. Madrid: Trotta, 
. Principia iuris: teoria del diritto e della democrazia. Roma: Laterza, 2007.

GUASTINI, Riccardo. Lezioni di teoria costituzionale. Torino: Giappichelli, 2001.

HABERMAS, Jürgen. Direito e democracia: entre facticidade e validade.

Tradução de Flávio Beno Siebeneichler, vol. II. Rio de Janeiro: Tempo Brasileiro, 1997.

LUCAS VERDÚ, Pablo. Estado liberal de derecho y Estado social de derecho. Madrid: Universidad de Salamanca, 1955.

MARCELLINO JÚNIOR, Júlio César. Princípio constitucional da eficiência administrativa: (des) encontros entre economia e direito. Florianópolis: Habitus, 2009.

PEREZ LUNÕ, Antonio Enrique. Derechos humanos, Estado de derecho y Constituición. 5. ed. Madrid: Tecnos, 1994.

PISARELLO, Geraldo. Del Estado social legislativo al Estado social constitucional: por una protección compleja de los derechos sociales. Revista de Teoría y Filosofía del Derecho, n. ${ }^{\circ}$ 15, Alicante: Isonomia, 2001, p. 81-107.

SARLET, Ingo Wolfgang. A eficácia dos direitos fundamentais. 9. ed. Porto Alegre: Livraria do Advogado, 2007.

SARLET, Ingo Wolfgang; TIMM, Luciano Benetti (Org.). Direitos fundamentais, orçamento e reserva do possiviel. 2. ed. Porto Alegre: Livraria do Advogado, 2010.

SARMENTO, Daniel Antonio de Moraes. O neoconstitucionalismo no Brasil: riscos e possibilidades. In: LEITE, George Salomão; SARLET, Ingo Wolfgang (Org.). Direitos fundamentais e Estado Constitucional: estudos em homenagem a J. J. Gomes Canotilho. São Paulo; Coimbra: Revista dos Tribunais; Coimbra Editora, 2009, p. 09-49.

VIANNA, Luiz Verneck, et al. A judicialização da política e das relações sociais no Brasil. Rio de Janeiro: Revan, 1999.

VIEHWEG, Theodor. Tópica y jurisprudencia. Traducción de Luis DíezPicazo Ponce de Leon. Madrid: Taurus, 1964. 